\title{
On the Diagnostic Role of Morphological Signs of Wild Rose (Rosa L.)
}

\section{U Umarov¹, M A Taysumov¹, M A Astamirova², R M Umarov², Ya S Gapaev", E R Baybatyrova ${ }^{2}$}

${ }^{1}$ Department of Biological Research, Kh. Ibragimov Complex Institute of the Russian Academy of Sciences, Grozny, Russia

${ }^{2}$ Department of Biological and Medical Research, Academy of Sciences of the Chechen Republic, Grozny, Russia

\section{Abstract}

Identification and systematics of species of wild rose (Rosa L.) are often associated with difficulties due to the diversity and variability of morphological features used in this process. They also arise in establishing genetic links between taxa of different ranks. Clarity in the diagnostic role of specific or group of characters is not only theoretical, but also of practical importance. Such an attempt is made on the example of species of the genus Rosa from different sections and subsections (R. canina.

Corresponding Author:

M U Umarov

umarovbiolog@mail.ru

Received: 25 October 2019

Accepted: 15 November 2019

Published: 25 November 2019

Publishing services provided by

Knowledge E

(c) M U Umarov et al. This article is distributed under the terms of the Creative Commons

Attribution License, which permits unrestricted use and redistribution provided that the original author and source are credited.

Selection and Peer-review under the responsibility of the AgroSMART 2019 Conference Committee.
R. danaiorum, R. ruprechtii, R. marschalliana, R. obtusifolia, R. svanetica, Rosa mollis, R. buschiana, R. pulverulenta, R pomifera, R. iberica, R. pimpinnefolia, etc.) of Chechnya and adjacent territories. The set of signs of the vegetative and generative sphere used in identifying species, subsections, sections has been considered. There was a lack of representativeness for the intraspecific diagnostics of such signs as: "free, immersed columns", or "sessile stigmas in the hemispherical head above the fetal throat", "occasionally solid sepals, with downward directed fruits" and others used in sectional diagnoses, because they are characteristic of species of different sections. The authors noted the heterogeneity of the authors' approach to the characterization of section rank taxa, the inadmissibility of the universal, and the need for a differentiated approach in using the same characteristics when identifying taxa of different levels.

Keywords: Rosa species, subsections, sections, morphological features, diagnostic role of characters.

\section{Introduction}

The significance of species of the genus wild rose (Rosa L.) in human life is well known. Since ancient times, in various nations of Europe, North Africa and Asia, many of them have been widely used in ornamental gardening and in medical practice. Due to the complex of useful properties, and now the types of wild rose are widely used for various purposes -- as decorative, medicinal, vitamin-bearing, food, as well as in breeding for the breeding of new varieties of roses [1--14]. 
The study of their systematics is of great theoretical and practical interest, due to the complexity and polymorphism of the genus Rosa L. The high variability of the species representing it is manifested in morphological characters, biology, ecology and chemical composition, including the content of vitamins.

\section{Material and Methods}

The objects of analysis were the herbarium collections of species of the genus Rosa L., collected during expeditionary research by members of the Chechen Republic Academy of Sciences. In total, 50 herbarium sheets of the species were collected, determined and mounted. In addition, processed herbarium samples from the funds of the Kh. Ibragimov Complex Institute of the Russian Academy of Sciences RAS and CSPU, collected in the study area in different years. To supplement the information on the availability of Rosa species, floristic reports on the Chechen Republic and adjacent territories have been studied [3, 4, 11--14].

Taxonomic identification of the collected plants was carried out according to the determinants of the Caucasian flora A.A. Grossheim $(15,16)$ and "Flora of the North Caucasus" A.I. Galushko [17]. The correctness of the definition was clarified according to the morphological descriptions from the "Flora of the USSR" [18] and "Flora of the Caucasus" [16], and for the species that were not included in these reports, according to the diagnoses of the original sources. In addition to these publications, to clarify the modern names of the species, a summary of S.K. Cherepanov was used [19].

\section{Results}

Floristic studies suggest identifying various ranks in a specific area of the entire diversity of the genus Rosa L. existing species. It is a prerequisite, or rather a stage of florogenetic and systematic constructions. The level of regional floristic research, as known, depends on two main circumstances. The first is the degree of objectivity in isolating the region of the study as a natural unit of zoning. The second is an understanding of the taxa volume of various ranks, especially the rank of a species. The selection of Chechnya in the natural floristic region seems quite reasonable. As for identifying within its borders and in adjacent territories of wild rose flora, there are great difficulties, caused by different understandings of the species, subspecies, varieties, forms, as well as the diversity in the interpretation of the relationship between them. 
Without dwelling on the general biological issues of interpreting the taxa of each of these ranks, we note that the fundamental difference lies in the degree of their discreteness. For wild roses it is obscured by the exceptional polymorphism of genus Rosa L. species, ability for interspecific and intersectional hybridization, as well as the presence of apomictic forms, especially within the section Caninae Gger. in Bull. [20].

The accumulation of random mutations in conditions of weakened selection -- the Wright effect [21] and, finally, the emergence of sustainable environmental groups of various qualifications in the variegated ecological-cenotic situation of mountain areas -- contribute to "blurring" of interspecific boundaries no less than any other factorrs. This is the main reasons for the genus inaccessibility for the systematic processing and taxonomic identification of its units. The application of traditional morphological criteria turned out to be insufficient. Nevertheless, it was the morphological signs that were leading in the diagnosis of taxa, and, over time, the authors followed the line of involving more and more particular signs and differences in the diagnoses. This is especially noticeable in a comparative analysis of the Caucasian wild rose from the Rubiginosae subsection described over the past 80--100 years.

This trend is characterized by the following data. To date, we know diagnoses of wild roses found in the North Caucasus, there are more than 700 morphological signs, among which are only signs of pubes pubescence -- 17, colors of corolla -- 11, sizes of leaves and leaflets -- 33 , leaf shapes -- 19, descriptions of leaf edges the plates and the structure of the teeth -- 31 , the pubescence of the leaves -- 32, the shape and size of the stipules -- 34, the pubescence of the stipules -- 30, the shape and size of the spikes -- 38, the size and pubescence of the pedicels -- 37, the position, shape and omission of the sepals, respectively -- $2,12,32$, the shape and size of hypanthia -- 30 , etc.

\section{Discussion}

Such a detalization of characters, interesting itself and pointing out researchers' vigilance, nevertheless inevitably leads to the conclusion of some form continuum within species of the genus Rosa L. Moreover, by improving and deepening the characteristics of the taxon, this detail obscures the real discreteness of the forms, the degree of their isolation.

Noting the abundance of diagnostic features used in the dog taxonomy, it should be noted that many authors have adopted different, and often not at all equivalent, diagnostic characteristics, signs. For example, the following signs are used in the diagnoses of the Caninae section: 
1. "The columns are free, submerged; stigmas form the sessile head above the fetal throat; sepals after flowering, bent, falling or erect over mature fruit (hypanthium), persist for a rather long time, external with feathery appendages, rarely whole; inflorescences are predominantly multi-flowered with more or less expanded bracts on the main pedicel; stipules coalesced, with a more or less extended tip; leaves of flowering shoots about 5--7 leaves, very rarely about 9 leaves; stems erect; spikes are hook-bent, very rarely straight, occasionally mixed with glandular needles" [20].

2. "Shrubs with erect stem; spikes are often the same, straight, curved or hookcrooked; middle leaves of flowering shoots mostly about 7 leaves. Flowers are usually in a multi-flowered inflorescence; sepals after flowering are bent down and fall before the fruits ripen or raised from above and lasted until the fruits ripen or with fruits; outer sepals pinnately dissected; the stigmas form a hemispherical head, usually not exceeding its outer edge of the stamen attachment line [19].

3. "Shrubs with upright branches; spikes are usually of the same type, straight, less often b. or m. curved, sickle-shaped to hook-shaped; middle leaves of flowering shoots of 5 or 7 leaves; flowers mainly in many-flowered inflorescences, sepals after flowering, then bent downwards and fall before maturing (reddened) fruits, then raised upwards and then usually preserved with red fruits; outer sepals pinnately dissected; the stigmas form a hemispherical head, usually not exceeding its attachment line of the sepals with its outer edge" [23].

4. "Erect shrubs with straight or arcuate-curved stems, covered with the same type or curved, less often with different types of thorns; the leaves are more often the number 7, thin.

Flowers with bracts in inflorescences, b. or m. many-flowered, sometimes they are single; sepals cirrus, with fruits directed downwards, remaining or falling early; the stigma head is sessile or pedicle, pubescent or naked" [21].

An analysis of these sectional diagnoses shows that the "free, immersed columns" are characteristic both for the species of the Caninae section and for the species of all sections belonging to the subgenus Rosa and Ghamaerhodon Dumort. (according to the system of V.G. Khrzhanovsky [23]). An alternative feature (columns, fused to a column) is found only in species of the subgenus Stylorhodon Dumort. -- white flowered subtropical species of wild rose, lianas from Southeast Asia.

"Stigmas form sessile, hemispherical head above the fetal throat". A.A. Lonachevsky analyzed these characteristics in detail in the species of the Caninae section and found them insufficiently representative for the intraspecific differentiation of R. canina. Our research shows that among the types and forms of this section there are almost 
all transitions of stigmas from sessile to rising above the throat on thin or dense legs; from naked (Rosa canina, R. danaiorum) to densely pubescent (R. ruprechtii); from barely diverging above the throat to dense conical in shape (R. marschalliana). Finally, the characteristic of the sepals: "sepals are rarely whole (Crepin), with the fruit directed downwards" (Galushko). The first remark virtually eliminates the boundary between the species of Caninae, Cinnamomeae, and Pimpinellifoliae sections. In the known species of the Caninae section, the sepals always have lateral appendages from cirrus (R. obtusifolia) to lanceolate (R. svanetica, etc.), and species that have lancet appendages (primarily from the Coriifoliae subsection) are closely related to species sections Cinnamomeae. As for the species of the section Pimpinellifiliae, the absence of lateral appendages on the sepals is one of the main diagnostic features distinguishing the types of this section from the others.

The second remark is valid only for the Caninae subsection species and the Rubiginosae subsection species group. The species of the wide European-Mediterranean subsections Vestitae and Coriifoliae are characterized by upwardly raised sepals.

The diagnostic material presented illustrates the proposition above about the heterogeneity of the authors' approach to the characterization of section rank taxa. The same picture is observed when describing taxa at the species level, with the only difference that in species diagnoses a much larger number of characters (up to 70) are used with their in-depth detailing.

The reasons for this cannot be seen in the subjectivity of the authors' views on the taxonomic significance of a particular trait and, apparently, should be sought in objective circumstances. First, even in the above descriptions, there is a clear tendency of diagnostics specification manifests itself, which is necessary for a deeper, more subtle characterization of objects and, possibly, their systematic integration. On the other hand, involving a growing number of characters to diagnose a taxon was dictated by the accumulation of floristic material over time: the description of new species required finding criteria for their differentiation and determining their relationship to taxa of higher rank. Noting these objective circumstances, characteristic of taxonomy in general, we must recognize that ecological-geographical and biological criteria in determining the kinship or separateness of evading forms still play a secondary role, despite the generally accepted view that the diagnosing species and finding their objective boundaries are based on the study of three lines of biological factors, three categories of traits: morphological and physiological; ecological and geographical; signs of direct biological connection and continuity between individuals -- genetic [24]. The formalization of the described species ecological-geographical characteristics of the 
genus has led to the fact that many species of Caucasian botanists are very difficult to diagnose because of the numerous morphological transitions between them in the absence of a clearly expressed geographical and physiological isolation. Most of these new species described, as we have said, belong to the Rubiginosae subsection.

\section{Conclusions}

Thus, based on the morphological, biological and ecological-geographical characteristics of wild rose, the following conclusions can be drawn. No morphological trait taken by itself, can be considered sufficiently reliable in the wild rose taxonomy due to its high variability. Not a single trait, but the entire sum of them, together with data relating to the ecology of the species, should be used in the delimitation of taxa. In this case, one should never look for the complete identity of the specimen with descriptions given in the "floras" or author's diagnoses, and also try to identify each collected specimen to a species, since wide hybridization is characteristic of genus Rosa L. species.

The same trait in different taxa of the genus can be mobile and relatively persistent (the nature of the thorionov thorns and the position of the sepals after flowering in species of the Cinnamomeae DC., Caninae Grep section, etc.).

The most important, from a taxonomic point of view, relatively stable are such traits as the character of thorns, flowering branches and turions (of the same type, mixed, scholar, single, etc.); the number of leaflets in the leaf and their consistency, shape and partly position relative to each other; the presence or absence of glands and their abundance; the nature of the jaggedness and the shape of the teeth; the presence of bracts, their size, number; the number of flowers in the inflorescence, partly the color of the petals; the nature of the sepal (shape, feathering, position with fruits); fetus shape; signs of the head of stigmas and pedicels, as well as for large taxonomic units (sections) and -- the shape of fruitlets (nuts).

The opinion about the broad ecological amplitude of the genus species is true only for a few of them -- the majority shows a clear connection with certain, usually arid, habitats. Plants show great dependency on temperature, soil moisture and air, to a lesser extent -- on the chemistry of the soil, the degree of solar insolation and, finally, the properties of the underlying rocks.

Species of the genus are found in all plant belts, ranging from alpine to steppe. Within the Alpine belt, they are only in its lowermost horizons, in the area of Rhododendron caucasicum and shrub-covered moraines (Rosa mollis Smith, partly R. buschiana Chrshan, and R. pulverulentha Bieb. (R. glutinosa auct)). 
The richest species of the genus Rosa L. are the oreoxerophyte belt, where $80 \%$ of the species live, most of them are concentrated here (R. pomifera Herrm., R. svanetica Grep., R. iberica Stev., R. pulverulentta Bieb., R. pimpinnefolia L. (R. spinosissima L.), and others.). In addition, they are found in many specimens, speaking as one of the important components of the thorny shrub groupings.

Each arid hollow of the North Caucasus, confined to the gorges of large rivers, is distinguished by its rhoological originality. Species that are common to one of them are an exception or are completely absent in the other basin.

\section{References}

[1] Grossheim, A.A. (1952). Plant resources of the Caucasus. Moscow: Moscow Society of Nature Testers, $634 \mathrm{p}$.

[2] Bigi, B. (1964). Cosmetic properties of eglantineol. Parfum., Cjsmet., Savons, no. 7, pp. 319--322.

[3] Trees and shrubs of the North Caucasus, 536 p., 1967.

[4] Galushko, A.I. Vegetative cover of Chechen-Ingushetia. Grozny: Chechen-Ingush. Prince publishing house, 1975, $118 \mathrm{p}$.

[5] Krzaczek, W., Krzaczek, T. (1979). Phenolic acids of the Rosa L. genus in Poland. Acta Soc. bot. polon, vol. 48, no. 2, pp. 327--336.

[6] Plant resources of the USSR. Flowering plants, their chemical composition, use: Family Hydrangeaceae -- Holaragaceae. (1987). Leningrad: Science, 326 p.

[7] Jantova, S., Nagy, M., Ruzekova, L., Grancia, D. (2000). Fabaceae, Oleaceae, Philadelphiaceae, Rosaceae and Staphyleaceae, Antibacterial activity. Phytother. Res., vol. 14, no. 8, pp. 601--603.

[8] Kumarasamy, Y., Cox, Ph.J., Jaspars, M., Rashid, M.F., Sarker, S.D. (2003). Bioactive flavonoid glycosides from Rosa canina. Pharm. Biol. (Lisse Netherlands), vol. 41, no. 4 , pp. 237--242.

[9] Rein, E., Kharazmi, A., Winter, K. (2004). Herbalremedy, Hyben Vitaly, a double-blind, placebo-controled, randomized tria. Phytomedicinw, vol. 11, no. 5, pp. 383--391.

[10] Plant Resources of Russia. Wild flowering plants, their component composition and biological activity, vol. 2. (2009). St. Peterburg; Moscow: Partnership of scientific publications, $513 \mathrm{p}$.

[11] Umarov, M.U., Taysumov, M.A. Abstract of the flora of the Chechen Republic. Grozny, 2011, 152 p. 
[12] Taysumov, M.A., Abdurzakova, A.S., Magomadova, R.S., Israilova, S.A. (2013). Contest of flora of the Terek-Kuma lowland. Grozny, $126 \mathrm{p}$.

[13] Taysumov, M.A., Umarov, M.A., Astamirova, M.A.-M. et al. (2015). Abstract of the flora of arid basins of Chechnya and Ingushetia. Grozny, 195 p.

[14] Umarov, M.U., Taysumov, M.A., Astamirova, M.A.-M. (2018). Rosaceae (Rosaceae Juss.) Flora of the Chechen Republic and their altitude-belt distribution. Grozny Natural Science Bulletin, no. 4(8), pp. 56--63.

[15] Grossheim, A.A. (1949). Determinant of Caucasian plants. Moscow: Soviet Science, $737 \mathrm{p}$.

[16] Grossheim, A.A. (1952). Flora of the Caucasus. Rosaceae -- Leguminosae, vol. 5. Moscow; Leningrad: Science, $453 \mathrm{p}$.

[17] Galushko, A.I. (1980). Flora of the North Caucasus. Determinant. vol. 2. Postov-onDon: Publishing house of Rostov University, $352 \mathrm{p}$.

[18] Flora of the USSR, vol. 10. (1941). Moscow; Leningrad: Publishing House of the Academy of Sciences of the USSR, $675 \mathrm{p}$.

[19] Cherepanov, S.K. (1995). Vascular plants of Russia and adjacent states. St. Peterburg: Peace and Family-95, 990 p.

[20] Crepin, F. (1972). Erimitiae monografiae rosarum, vol, 10. New-York, 836 p.

[21] Galushko, A.I. (1959). Their Authorized. PhD dissertation thesis. Leningrad, 26 p.

[22] Yuzepchuk, S.V. (1941). The genus Rosa L. In the book: Flora of the USSR, vol. X, pp. 431--506.

[23] Khrzhanovsky, Z.G. (1958). Roses (Phylogeny and Systematics). Moscow: Soviet Science, $497 \mathrm{p}$.

[24] Skvortsov, A.K. (1968), Willow USSR. Moscow: Hauka, 262 p. 